\title{
Tips To Minimize Workplace Negativity
}

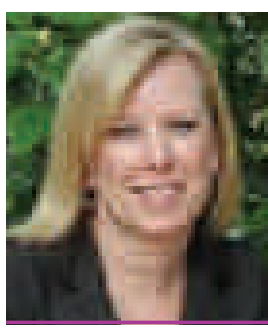

Trudi Charest, RO

Trudi Charest is the Co-Founder of 4ECPs, a business resource company for eye care professionals. $4 E C P$ s has three divisions - Jobs4ECPs, Marketing4ECPs \& Training4ECPs. She is well known for designing; developing and facilitating training and marketing programs to Eye Care Professionals across North America and is a Licensed Optician with over 25 years of extensive eyecare experience. She also holds a Human Resource Management certificate from the University of Calgary. She is an international speaker, author, industry consultant and business innovator. Check out their website at www.4ecps.com or email Trudi at trudi@4ecps.com.

$\mathrm{N}$ egativity in the workplace can be detrimental to patient retention, not to mention your pocketbook. It only takes one negative experience for a patient to decide to try another eye doctor or optical store. There are a lot of choices out there for eyewear and eye care, so you have to ensure that you minimize any issues regarding negative behavior by your staff.

Negativity typically manifests as one or two employees with attitude or authority issues. They don't like being told what to do, they don't like the way things work or they just don't like much, period. They are generally negative in all regards, and they don't stop complaining. These employees are like weeds that will keep spreading if not pulled. Not only can these malcontents affect your customers, your great employees may also eventually leave if you don't address negativity issues in your workplace. A McKinsey study concluded that $59 \%$ of employees would be "delighted" if managers dealt with problem employees. In reality, however, only $7 \%$ of employees believe that their companies are actually doing a good job in this regard.

Here are 5 Tips to Minimize Negativity:

\section{Don't Let Negativity Slide}

Negativity grows and becomes an issue in a practice because it is often ignored. If you don't address a negative or abusive attitude in an employee, other employees are going to take offense and may quit. You don't need a turnover problem on top of a negativity issue. Address the problem head-on and as soon as possible. Any delay can cause the problem to escalate.

\section{Set the Standard for Positivity}

Leaders set the tone, so set a tone of positivity. A positive attitude at all times should be a non-negotiable standard of practice at your office. Everyone can have an off day, but a series of consistently bad days during which an employee exhibits a bad mood may be an indication of their overall attitude and demeanor. People rarely change, so what you see is likely what you're going to get. Find ways to uncover whether people are positive or negative during the initial hiring interview so that you'll begin with the right people in the first place initially.

\section{Treat Everyone the Same}

Hold everyone to the same standards and expectations. Everyone in the office is expected to be happy, friendly and positive during all transactions with patients and colleagues. Don't condone negativity in any way. If you do so once, your problem employees may look for an opening to be negative again.

\section{Respond to Employee Concerns}

As a leader, it is not always possible for you to see and hear everything. One option to address this limitation is to create an open-door policy so your staff will feel comfortable coming to you for any situation. If any of your employees are acting negative or abusive, your staff should feel safe telling you what is going on. If they do confide in you, it is imperative that you take action in some way. By not responding, you may create an entirely different set of issues and challenges. Let the employee who reported the problem know what you plan to do and when. 


\section{Involve Staff in Office Policy-Making}

Involving staff in the development of office policies and guidelines helps set expectations for how they should present themselves at the office. If they have been involved in creating an office policy handbook that outlines how a positive attitude and demeanor are expected at all times, they are more likely to help promulgate this behavior. At the very least, your staff will know that a standard has been set, and if you have to address any problems, they can't say they were unaware of the office policies.

Final thoughts - If you present a positive attitude at all times and don't accept anything less from your employees, you are already well on the way to building a positive, supportive work environment.

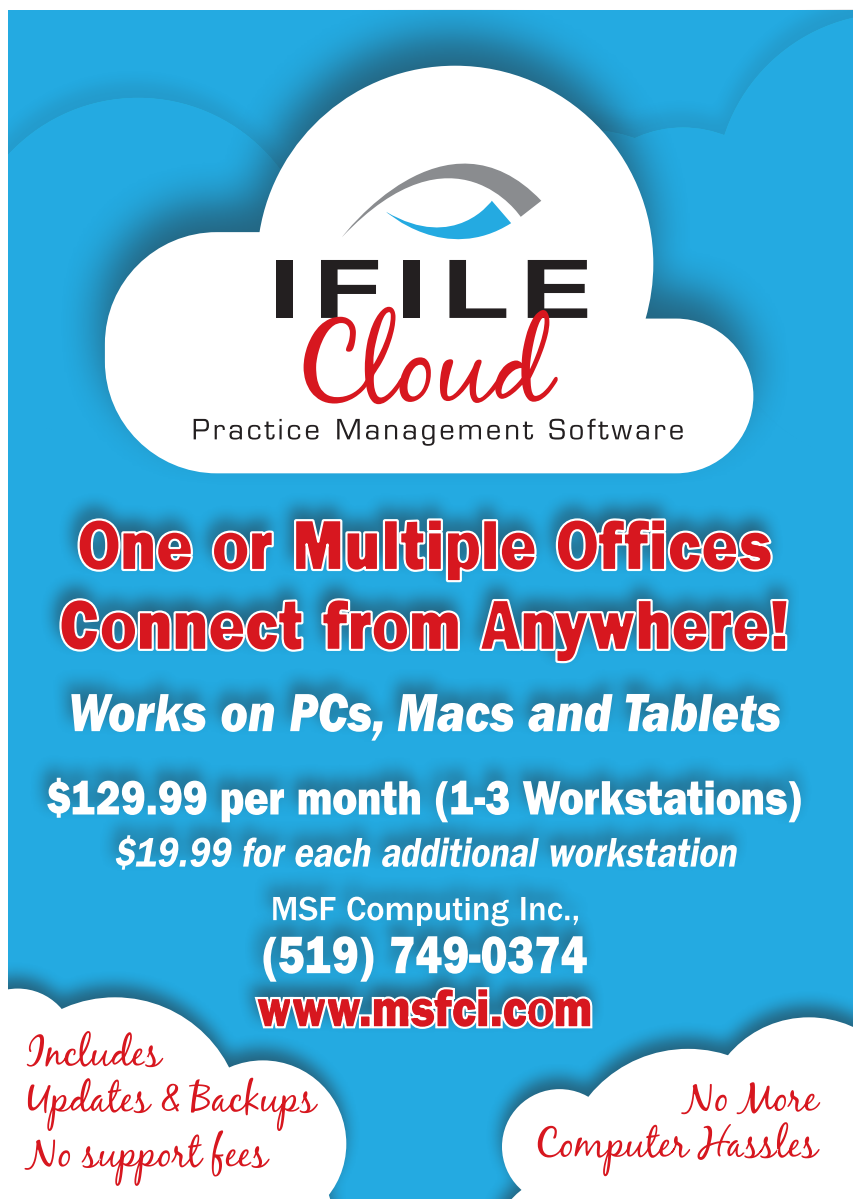

